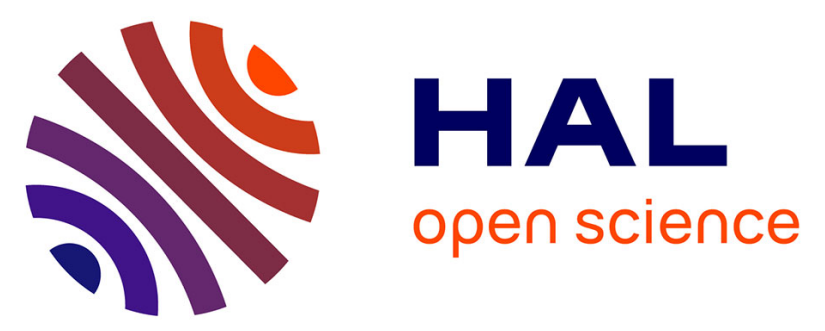

\title{
Characteristics and Management of IgA Vasculitis (Henoch-Schonlein) in Adults Data From 260 Patients Included in a French Multicenter Retrospective Survey
}

Alexandra Audemard-Verger, Benjamin Terrier, Agnès Dechartres, Johan

Chanal, Zahir Amoura, Noémie Le Gouellec, Patrice Cacoub, Noemie Jourde-Chiche, Geoffrey Urbanski, François Augusto, et al.

\section{To cite this version:}

Alexandra Audemard-Verger, Benjamin Terrier, Agnès Dechartres, Johan Chanal, Zahir Amoura, et al.. Characteristics and Management of IgA Vasculitis (Henoch-Schonlein) in Adults Data From 260 Patients Included in a French Multicenter Retrospective Survey. Arthritis \& rheumatology, 2017, 69 (9), pp.1862-1870. 10.1002/art.40178 . hal-01787239

\section{HAL Id: hal-01787239 \\ https://hal-amu.archives-ouvertes.fr/hal-01787239}

Submitted on 14 May 2018

HAL is a multi-disciplinary open access archive for the deposit and dissemination of scientific research documents, whether they are published or not. The documents may come from teaching and research institutions in France or abroad, or from public or private research centers.
L'archive ouverte pluridisciplinaire HAL, est destinée au dépôt et à la diffusion de documents scientifiques de niveau recherche, publiés ou non, émanant des établissements d'enseignement et de recherche français ou étrangers, des laboratoires publics ou privés. 


\section{Characteristics and management of IgA vasculitis (Henoch-Schönlein purpura)}

\section{in adults: data from the 260 patients included in the IGAVAS survey}

Alexandra Audemard-Verger ${ }^{1,{ }^{*}}$, Benjamin Terrier $^{1,{ }^{*}}$, Agnès Dechartres $^{2}$, Johan Chanal $^{3}$, Zahir Amoura ${ }^{4}$, Noémie Le Gouellec ${ }^{5}$, Patrice Cacoub ${ }^{6}$, Noémie JourdeChiche $^{7}$, Geoffrey Urbanski ${ }^{8}$, Jean-François Augusto ${ }^{9}$, Guillaume Moulis ${ }^{10}$, Loic Raffray $^{11}$, Alban Deroux ${ }^{12}$, Aurélie Hummel ${ }^{13}$, Bertrand Lioger ${ }^{14}$, Mélanie Catroux ${ }^{15}$, Stanislas Faguer ${ }^{16}$, Julie Goutte ${ }^{17}$, Nihal Martis $^{18}$, François Maurier ${ }^{19}$, Etienne Rivière $^{20}$, Sébastien Sanges ${ }^{21}$, Aurélie Baldolli ${ }^{22}$, Nathalie Costedoat-Chalumeau ${ }^{1}$,

Mélanie Roriz ${ }^{14}$, Xavier Puéchal ${ }^{1}$, Marc André ${ }^{23}$, Christian Lavigne ${ }^{8}$, Boris Bienvenu $^{22}$, Arsène Mekinian ${ }^{24}$, Elie Zagdoun ${ }^{25}$, Charlotte Girard ${ }^{26}$, Alice Bérezné1, Loïc Guillevin ${ }^{1}$, Eric Thervet ${ }^{27, \#}$, Evangéline Pillebout ${ }^{28, \#}$, on behalf of the French Vasculitis Study Group (FVSG)

* These authors contributed equally to this work.

\# These authors contributed equally to this work.

1 A. Audemard-Verger, MD, B. Terrier, MD-PhD, N. Costedoat-Chalumeau, MD-PhD, X.Puechal, MD-PhD, A.Bérezné, MD, L. Guillevin, MD: Department of Internal Medicine, National Referral Center for Rare Systemic Autoimmune Diseases, Hôpital Cochin, Assistance Publique-Hôpitaux de Paris (AP-HP), Université Paris Descartes, Paris, France.

2 A. Dechartres, MD-PhD : Center for clinical epidemiology, Hôtel Dieu, Assistance Publique-Hôpitaux de Paris (AP-HP) Paris, France.

3 J. Chanal, MD: Department of Dermatology, Hôpital Tarnier, Assistance PubliqueHôpitaux de Paris (AP-HP), France.

4 Z. Amoura, MD-PhD: Department of InternalMedicine, Hôpital Pitié-Salpétrière, Assistance Publique-Hôpitaux de Paris (AP-HP), Paris, France.

5 N. Le Gouellec, MD: Department of Internal Medicine and Nephrology, $\mathrm{CH}$ de Valenciennes, France.

6 P. Cacoub, MD-PhD: Department of Internal Medicine, Hôpital Pitié-Salpétrière, Assistance Publique-Hôpitaux de Paris (AP-HP), Paris, France

$7 \mathrm{~N}$. Jourde-Chiche, MD-PhD: Department of Nephrology, Assistance PubliqueHôpitaux de Marseille (AP-HM), France.

8 G.Urbanski, MD, C.Lavigne, MD: Department of Internal Medicine and vascular disease, CHU d'Angers, France.

$9 \mathrm{JF}$. Augusto, MD-PhD: Department of Nephrology, CHU d'Angers, France.

10 G.Moulis, MD-PhD: Department of of Internal Medicine, CHU de Toulouse, France.

This article has been accepted for publication and undergone full peer review but has not been through the copyediting, typesetting, pagination and proofreading process which may lead to differences between this version and the Version of Record. Please cite this article as an

'Accepted Article', doi: 10.1002/art.40178

(C) 2017 American College of Rheumatology

Received: Jun 12, 2016; Revised: May 12, 2017; Accepted: J un 08, 2017

This article is protected by copyright. All rights reserved. 
11 L.Raffray, MD-PhD: Department of Internal Medicine, $\mathrm{CHU}$ de la Réunion, France. 12 A. Deroux, MD: Department of Internal Medicine, CHU de Grenoble, France.

13 A. Hummel, MD: Department of Nephrology, Hôpital Necker, Assistance PubliqueHôpitaux de Paris (AP-HP), Paris, France.

14 B.Lioger, MD, M. Roriz, MD: Department of Internal Medicine, CHU de Tours, France.

15 M. Catroux, MD: Department of Internal Medicine, CHU de Poitiers, France.

16 S. Falguer, MD-PhD: Department of Nephrology and Organ Transplantation, CHU de Toulouse France.

17 J.Goutte, MD:Department of Internal Medicine, CHU de St Etienne, France.

18 N. Martis, MD: Department of Internal Medicine, CHU de Nice, France.

19 F. Maurrier, MD : Department of InternalMedicine, Hôpitaux privés de Metz, France.

20 E. Rivière: $M D, P h D, M A(E d)$ : Department of InternalMedicine, CHU de Bordeaux, France.

21 S. Sanges, MD: CHU Lille, Département de Médecine Interne et Immunologie Clinique, F-59000 Lille, France.

22 A. Baldolli, MD, B. Bienvenu, MD-PhD: Department of Internal Medicine, CHU de Caen, France.

23 M. André, MD-PhD: Department of Internal Medicine, CHU de Clermont-Ferrand, France.

24 A. Mekinian, MD-PhD: Department of Internal Medicine, Hôpital de Bondy, Assistance Publique-Hôpitaux de Paris (AP-HP), France.

25 E. Zagdoun, MD: Department of Nephrology, CH de St Lo, France.

26 C. Girard, MD: Department of Internal Medicine, CHU de Lyon, France.

27 E. Thervet, MD-PhD: Department of Nephrology, Hôpital Européen Georges Pompidou, Assistance Publique-Hôpitaux de Paris (AP-HP), Université Paris Descartes, Paris, France

28 E. Pillebout, MD-PhD: Department of Nephrology, Hôpital Saint Louis, Assistance Publique-Hôpitaux de Paris (AP-HP), Université Paris Descartes, Paris, France

Correspondence: Dr. Benjamin Terrier, Department of InternalMedicine, National Referral Center for Rare Systemic Autoimmune Diseases, Hôpital Cochin, 27, rue du Faubourg Saint-Jacques, 75679 Paris Cedex 14, France.

Phone: +33 (1) $5841 \quad 14$ 61; Fax: +33 (1) $5841 \quad 14$ 50; $\quad$ E-mail:

benjamin.terrier@aphp.fr.

Keywords: IgA vasculitis, Henoch-Schönlein purpura, characteristics, prognosis,

treatment

Conflict of interest: None 
Fundings: None

Words count: Abstract 299 words; Manuscript 3408 words

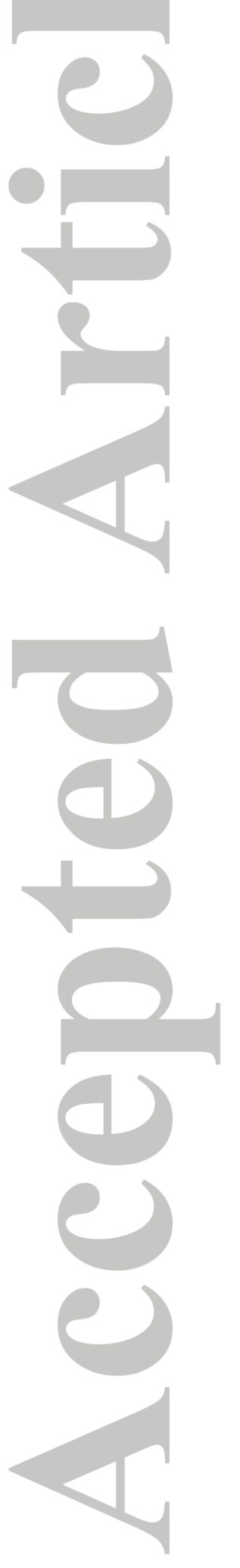




\section{Abstract (249 words)}

Objectives: Data on adult $\lg A$ vasculitis $(\lg A V)$ are scarce. This survey was designed to better define clinical spectrum and efficacy of treatments in this population.

Methods: We analyzed data from 260 patients with IgAV included in a French multicenter retrospective survey.

Results: Mean age at diagnosis was $50.1 \pm 18$ years, and $63 \%$ were male. Baseline manifestations included purpura (100\%), arthralgia (62\%), glomerulonephritis $(70 \%)$ or gastro-intestinal involvement $(53 \%)$. Thirty percent showed at baseline renal failure. In univariate analysis, response was $80 \%(n=64 / 80)$ in patients treated with corticosteroids (CS) alone compared to $77 \%(n=23 / 30)$ in patients treated with cyclophosphamide (CYC) and 10/17 (59\%) treated with colchicine $(P=0.17)$.

Multivariable analysis showed that patients treated with CS or CS plus CYC were more effective than colchicine in achieving response using different statistical analysis: logistic regression model [OR (95\% Cl) $3.68(1.10-12.33), P=0.03]$, inverse probability weighting on Propensity Score (PS) [OR 3.75 (1.28-10.99), $P=0.02$ ]. Efficacy of CS plus CYC versus CS were discordant according to the method used. The use of multivariable logistic regression model [OR $0.88(0.29-2.67), P=0.82$ ] did not demonstrate difference, in contrast, inverse probability weighting on PS with [OR 1.79 (1.00-3.20), $P=0.049$ ] showed that CS plus CYC were more effective.

Conclusion: This series constitutes the largest series reported so far in the literature of adults IgAV. It provides data on clinical and histological presentation and therapeutic efficacy, suggesting that CS alone appears to be a reasonable first-line therapy in patients with IgAV, while the benefit of adding CYC to CS remains uncertain. 


\section{Introduction}

Immunoglobulin A (IgA) vasculitis, formerly called Henoch-Schönlein purpura, is an immune complex small vessel vasculitis with IgA1-dominant immune deposits (1). $\lg A$ vasculitis $(\lg A V)$ is the most common systemic vasculitis in childhood with an annual incidence of 3 to 26 per 100000 children (2). In adults, the disease is less common with an annual incidence of 0.1 to 1.8 per 100000 individuals $(3,4),(5)$. IgAV frequently involves the skin, the gastrointestinal tract, the joints with arthralgias and/or arthritis, and the kidneys (6). Gastrointestinal tract and renal involvements represent the main causes of morbidity and mortality in adults. In a large study of 250 IgAV in adults, $11 \%$ of patients reached end-stage renal disease (ESRD), $13 \%$ had severe renal failure with an estimated glomerular filtration rate (eGFR) $<30$ $\mathrm{mL} / \mathrm{min} / 1.73 \mathrm{~m}^{2}$, and $14 \%$ had moderate renal failure with eGFR<50 $\mathrm{mL} / \mathrm{min} / 1.73 \mathrm{~m}^{2}(7)$. Factors associated with evolution to ESRD included baseline renal function, baseline proteinuria $>1$ or $1.5 \mathrm{~g} /$ day, macroscopic hematuria, hypertension, and proteinuria $\geq 1$ g/day during follow-up (7-9). In a study from Southern European population, hematuria at disease onset, renal involvement during the course of the disease, anemia at the time of diagnosis and onset of the disease in summer were more common in patients with renal sequelae (10). On renal biopsy, degree of interstitial fibrosis, sclerotic glomeruli and fibrinoid necrosis were also associated with a poor renal prognosis (7).

Treatment has been poorly investigated in adults. Management of $\lg A V$ is often symptomatic because of the frequent benign course of the disease with spontaneous remission. However, in case of severe involvement with organ and/or life-threatening complications, corticosteroids (CS) or/and immunosuppressive drugs are often initiated. Pillebout et al. conducted the only prospective, multicenter, open 
label trial in adults, comparing CS alone versus CS plus cyclophosphamide (CYC) in patients with severe IgAV (11). Fifty-four patients with biopsy-proven IgAV and severe manifestations, including proliferative glomerulonephritis and/or severe gastrointestinal manifestations, were included. At 12 months, no difference was found between the 2 groups in terms of remission rate, renal outcomes and adverse events. However, overall survival at 12 months tended to be better in the CS plus CYC group compared to CS alone $[96 \%(95 \% \mathrm{Cl} 89-100)$ vs. $79 \%$ (95\% Cl 64-93); $\mathrm{P}=0.08$ ). Hence, the optimal therapeutic strategy has yet to be defined in adults.

To better define the clinical spectrum and the efficacy of treatments in IgAV in adults, a nationwide survey was initiated in France in 2013. Data from the 260 cases of IgAV in adults included in the IGAVAS survey are reported here.

\section{Patients and methods}

\section{Patients}

This multicentric retrospective survey was conducted in French university and general hospitals in departments of Internal Medicine, Nephrology, Dermatology and Rheumatology. The study was performed in accordance with ethical standards of the Helsinki Declaration, and was approved by Institutional Review Board. The inclusion criteria for the study were (1) age >18 years old, (2) IgA vasculitis, and (3) diagnosis of IgAV between January 1990 and January 2015. Patients were considered to have IgAV if they presented (1) purpura, (2) histologically proven small vessels vasculitis, (3) IgA histologically proven deposits and (4) involvement of at least one organ among kidney, joint, or intestinal tract. Exclusion criteria were IgAV associated with a diagnosis of cancer in the 5 previous years before vasculitis onset.

\section{Clinical and biologic data}


Clinical and biologic data were recorded for each patient at the time of the initial evaluation, during follow-up ( 6 and 12 months after initial evaluation), and at the end of follow-up, by the practitioners in charge of the patients with the use of a standardized form. Laboratory assessment included in particular the determination of serum creatinine level and a urinalysis to screen for hematuria and a 24-hour urine protein examination. Renal failure was defined as an eGFR $<60 \mathrm{~mL} / \mathrm{min} / 1.73 \mathrm{~m}^{2}$, assessed with the Modified Diet in Renal Disease equation (12). Proteinuria was defined as 24-hour urine protein excretion $>0.5 \mathrm{~g} /$ day, and hematuria was defined as 10 red cells $/ \mathrm{mm}^{3}$ in the urine considered as macroscopic if $>1500$ red cells $/ \mathrm{mm}^{3}$. Elevated IgA levels was defined as $\lg \mathrm{A}>3.5 \mathrm{~g} / \mathrm{L}$.

\section{Histological data}

Histological data (skin and renal biopsies) were recorded at the time of diagnosis. Pathology reports for renal biopsies were examined by two independent nephrologists (ET and EP) blinded to the clinical features. According to the presence of focal or diffuse distribution, extracapillary proliferation, number of glomeruli involved, interstitial fibrosis, proportions of glomeruli involved by crescents, fibrinoid necrosis and global sclerosis, all biopsies were classified according to the classification previously described by Pillebout et al. (7).

\section{Response to therapy}

The response to therapy of IgAV was defined by analysing the course of the following main clinical signs: skin involvement (purpura), articular manifestations (arthralgia and/or arthritis), gastrointestinal symptoms and renal involvement (normalization or improvement of eGFR, proteinuria and hematuria). Response were evaluated by 2 independent physicians (AAV and BT) blinded to the treatment received. A complete response was defined as an improvement in all baseline clinical manifestations and 
in case of renal involvement by a proteinuria $<0.5 \mathrm{~g} / \mathrm{d}$, the disappearance of hematuriaand no decrease of the glomerular filtration rate (GFR) greater than $20 \%$ from baseline. A partial response was defined as an improvement in at least one-half of the baseline clinical manifestations, and in case of renal involvement as an improvement of proteinuria $>50 \%$ of the baseline value, disappearance or not of hematuria, and no decrease of the GFR greater than $20 \%$ from baseline. All others patients were classified as non-responder. Relapse was defined as the reappearance of clinical signs of vasculitis, occurring after a period free of symptoms of at least a one month. Minor relapse was defined by increase of prednisone no greater than 20 $\mathrm{mg} /$ day and major relapse by addition of immunosuppressive drug or increase of prednisone greater than $20 \mathrm{mg} / \mathrm{day}$. Others patients were considered as having no relapse.

\section{Statistical analysis}

Descriptive statistics included the mean (SD) or median [Q1; Q3] when appropriate for continuous variables, and frequency (percentage) for categorical variables. Univariate analysis included the Chi2 or Fisher exact test as appropriate to compare categorical variables and the nonparametric Mann-Whitney test to compare continuous variables. To evaluate efficacy of therapeutic regimens, we performed a multivariable logistic regression model to assess factors independently associated with response to therapy. All important factors in the literature as well as those associated with being treated or with response to therapy in univariate analysis were included in the final model. Correlated variables were not all entered in the model to avoid the risk of collinearity. To account for a potential indication bias (ie, patients treated with corticoids or CYC may be more severe than those treated with colchicine only), we also estimated a propensity score corresponding to the probability of being 
treated with corticosteroids or CYC rather than Colchicine according to patients' characteristics (age, gender, gastro-intestinal bleeding, creatininemia, proteinuria, necrotic purpura) using a logistic regression model $(13,14)$. We performed an evaluation of the distributions of propensity scores by treatment groups checking for sizeable overlap among the treatment groups (ie, it is not possible to use a propensity score when the two groups are too different, this is why, it is important to check whether the two groups overlap). There are several ways to use the propensity score in analysis including adjustment on propensity score as a covariate in the model, matching of individuals treated and not treated on their propensity score and inverse probability weighting by propensity score. The 2 preferred methods are matching and weighting (15). However, it is not always possible to use matching as participants not matched (ie, patients treated and not treated for which the propensity score is not the same) do not participate in analysis. In this study, we used both adjustment on propensity score and inverse probability weighting on propensity score in logistic regression models to assess whether a treatment by corticosteroids or CYC was associated with a better response compared to colchicine and to assess whether a treatment by CYC was associated with a better response compared to corticosteroid alone. Because inverse probability weighting analysis may be sensitive to extreme propensity scores $(13,14)$, we did a sensitivity analysis excluding the $5 \%$ of patients with the lowest propensity scores.

Adjusted Odds ratios for all covariates in the model without propensity score are showed in the Supplemental Material Table 1.

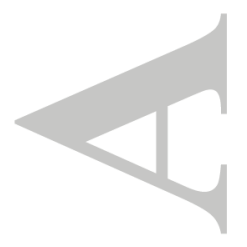




\section{Results}

Of the 304 patients assessed for eligibility in the IGAVAS survey, 260 patients were included. Forty-four patients were excluded because of absence of proven IgA deposits $(n=27)$, absence of proven vasculitis $(n=4)$, concomitant cancer $(n=6)$ or missing data $(n=7)$.

\section{Clinical and biological patient characteristics}

The characteristics of the 260 patients with $\lg \mathrm{AV}$ are shown in Table 1 . The mean age at diagnosis was $50.1 \pm 18$ years and 164 patients $(63 \%)$ were male. Clinical manifestations included constitutional symptoms in 87 patients (33\%), cutaneous involvement with purpura in all patients (100\%), arthralgia/arthritis in 159 patients (61\%), renal involvement in 182 patients $(70 \%)$ and gastrointestinal involvement in 137 patients $(53 \%)$. Thirty percent of the patients showed renal failure (eGFR<60 $\mathrm{ml} / \mathrm{min} / 1.73 \mathrm{~m}^{2}$ ) at baseline. Patients with renal involvement displayed a 90 $\mathrm{mL} / \mathrm{min} / 1.73 \mathrm{~m}^{2}[66 ; 110]$ median eGFR, a $1.5 \mathrm{~g} /$ day median proteinuria level $[0.6 ; 3]$, and $88 \%$ presented hematuria. The median serum $\operatorname{lgA}$ level was $3.6 \mathrm{~g} / \mathrm{L}[2.7 ; 4.8]$ and $85 / 159$ patients (53\%) presented elevated IgA levels.

Anti-neutrophil cytoplasmic antibodies (ANCA) were detected in 9/225 patients (4\%) and antinuclear antibodies (ANA) in 33/231 patients (14\%), both without any specificity (data not shown).

\section{Histological features}

The characteristics of skin and renal biopsies performed in the patients are summarized in Table 2. Skin biopsy was performed in 222 patients (85\%), and renal biopsy in 144 of the 182 patients with kidney involvement (79\%). The skin biopsy demonstrated leukocytoclastic vasculitis in 205 patients (92\%). Direct immunofluorescence revealed IgA and complement deposition in blood vessels of the upper 
dermis in $174 / 216(81 \%)$ and $47 / 222$ (21\%) patients. In 6 skin biopsies, direct immuno-fluorescence was not performed. The renal biopsy demonstrated IgA mesangial deposits in 142/144 patients (99\%) and extracapillary proliferation in $59 / 143$ patients $(41 \%)$. Of the pathology reports that were independently reviewed $(n=67)$, majority of patients were classified as class 2 in $33 / 67(49 \%)$, i.e. a focal and segmental glomerulonephritis with segmental endo- and extracapillary proliferation involving less than $50 \%$ of the glomeruli, and class $3 a$ in $18 / 67$ (27\%), i.e. an endocapillary proliferative glomerulonephritis with moderate endocapillary proliferative lesions.

\section{Treatments used}

Treatments used were colchicine only in 27 patients, corticosteroids alone in 122 patients, and corticosteroids in combination with cyclophosphamide in 35 patients. Ten patients received various therapies, including dapsone in 4 cases, rituximab in 2 cases, mycophenolate mofetil in 2 cases and hydroxychloroquine in 2 cases. Sixtysix patients did not receive a specific treatment.

Baseline characteristics of the 250 patients according to the treatment used (except the 10 patients with various treatments) are shown in Table 3. Compared to patients who received no treatment or who received only colchicine, patients treated with CS or CS plus CYC were more frequently male $(P=0.004)$, presented at baseline more frequently with necrotic purpura $(P=0.006)$, renal involvement $(P=0.0001)$, higher levels of proteinuria $(P<0.0001)$ and hematuria $(P=0.0005)$, more frequent endo- and extracapillary proliferation $(P<0.0001)$, and more frequent and severe gastrointestinal tract involvement $(\mathrm{P}<0.0001)$. These factors, as well as significant factors previously described in the literature were included in the multivariable logistic regression model and the estimation of the propensity score. 


\section{Effect of therapeutic regimen on response to treatment and outcome}

Of the 260 patients, 132 patients received either colchicine, CS or CS plus CYC, and had a follow-up $>6$ months. Follow-up data were missing for 5 patients, who did not differ from the remaining patients (data not shown). Finally, 127 patients were analyzed. Patients characteristics according to the achievement of partial or complete response in comparison with those with no response within the first 12 months of follow-up are summarized in Table 4.

In univariate analysis, no characteristic or treatment was significantly associated with the achievement of partial or complete response. Partial or complete response was obtained in $64 / 80$ patients $(80 \%)$ treated with CS, $23 / 30$ patients $(77 \%)$ treated with CS plus CYC, and 10/17 (59\%) treated with colchicine $(P=0.17)$.

Among the 66 patients who did not receive any treatment, 34 could be analysed because they were followed-up for at least 6 months. In univariate analysis $85 \%$ $(n=29 / 34)$ presented spontaneous remission at month 6 and/or 12 .

Although patients were not comparable in each treatment group, Supplemental Material Table 2 shows that cutaneous and renal manifestations persisted between month 6 to 12 in 7 to $41 \%$ and 10 to $40 \%$ according to treatments used, respectively. We then evaluated the efficacy of treatments after adjusting for confounding factors. The results of the multivariable logistic regression model, adjusted for gender, creatinine, proteinuria, digestive bleeding and necrotic purpura. The multivariable propensity score adjusted logistic regression model, and the inverse probability weighting on propensity score, with or without sensitivity analysis excluding outliers are indicated in Figures 1 and 2. 
Treatment with CS or CS plus CYC were more effective than colchicine in achieving a partial or complete response using multivariable logistic regression model [OR $(95 \% \mathrm{Cl}) 3.68(1.10-12.33), \mathrm{P}=0.03]$, the multivariable propensity score adjusted logistic regression model [OR $(95 \% \mathrm{Cl}) 3.58(1.07-11.94), \mathrm{P}=0.04]$ and inverse probability weighting on propensity score [OR $(95 \% \mathrm{Cl}) 3.75(1.28-10.99), \mathrm{P}=0.02$ ] (Figure 1).

We also compared the efficacy of CS plus CYC versus CS (Figure 2) and found discordant results according to the method used. The use of multivariable logistic regression model [OR $(95 \% \mathrm{Cl}) 0.88(0.29-2.67), \mathrm{P}=0.82]$ and the multivariable propensity score adjusted logistic regression model [OR $(95 \% \mathrm{Cl}) 0.90$ (0.29-2.78), $P=0.86$ ] did not demonstrate any difference between the 2 therapeutic strategies in achieving a partial or complete response. In contrast, the use of inverse probability weighting on propensity score with [OR $(95 \% \mathrm{Cl}) 1.79(1.00-3.20), \mathrm{P}=0.049$ ] or without sensitivity analysis excluding outliers [OR $\left(\begin{array}{lll}95 \% & \mathrm{Cl}\end{array}\right) 2.33$ (1.29-4.18), $\mathrm{P}=0.005$ ] showed that treatment with $\mathrm{CS}$ plus CYC were more effective than CS in achieving a partial of complete response.

\section{Follow-up of patients}

After a median follow-up of 17.2 months [9.1-38.3] corresponding to 593 patientyears, 8 patients died, including 3 deaths directly related to $\operatorname{lgAV}$ (2 mesenteric ischemia and 1 multivisceral failure). Eight patients experienced end stage renal failure treated by renal transplantation $(n=2)$ or dialysis $(n=6)$. Among patients who received a treatment, data concerning relapse during the first 12 months after treatment were available in 107 patients and showed 15 minor relapse (14\%) and 9 $(8 \%)$ a major relapse. Among untreated patients, data concerning relapse during the 
first 12 months of follow-up were available in 10 patients and showed one minor relapse $(10 \%)$.

\section{Discussion}

It has been clearly reported that the clinical presentation and prognosis of adults IgAV differs from that of children. Because randomized controlled trials are lacking in the literature, evaluation of efficacy of the different therapeutic regimens, which is mandatory to improve the management of IgAV patients, was a main goal of the IGAVAS survey. To better define the clinical spectrum and the therapeutic management of IgAV, we analyzed the data from 260 patients included in the French multicenter and transdisciplinary IGAVAS survey, which constitutes the largest series of adults reported so far in the literature.

Patients in our study were comparable to those previously described by others (16-20). They were predominantly male, while mean age was 50 years compared to 32 to 44 years in previous series (16-20) and 48 years in a northwestern Spanish epidemiologic study (5). The incidence of cutaneous, articular and gastrointestinal tract involvement were also comparable with those described in others series, except for the renal involvement which was more prevalent in our series $(70 \%$ versus 30 to $60 \%$ in others series) $(16-20)$. This finding is probably related to the high rate of patients that were included by nephrologists in our survey. Considering laboratory findings, the prevalence of increased serum IgA levels (53\%) was slightly more important than in other series (31 to $52 \%)(16-20)$.

Treatment of IgAV is often symptomatic because the disease course is usually

benign. In more severe forms, some reports dealt with the use of CS and immunosuppressive agents (21), but randomized controlled trials are lacking in adult 
$\operatorname{lgAV}$. Corticosteroids are effective on arthralgia and abdominal pain and there is a considerable controversy on the benefit of corticosteroids to treat renal involvement and prevent evolution to end-stage renal disease especially in both pediatric and adult population (22-25). In adult IgAV with severe nephritis, Ren et al. suggested that mycophenolate mofetil could be useful for inducing remission and as steroidsparing agent, but long-term effect on renal function is not known (26). By analogy with severe autoimmune diseases, CYC has been used in patients with organ- or lifethreatening IgAV manifestations. Pillebout et al. compared CS with or without CYC in severe adults IgAV, in a prospective open-label trial (11). Fifty-four patients with biopsy proven IgAV and severe manifestations were included and randomized to receive CS alone or CS plus CYC. At 6 months, no difference was found between the 2 groups for the primary endpoint, i.e. the achievement of complete disease remission defined as zero on the Birmingham Vasculitis Activity Score (BVAS) (27), with no persistent or new clinical and/or biological vasculitis manifestation. The secondary endpoints, i.e. renal outcome, deaths, and adverse events, also did not differ at 12 months. However, only 54 patients of the 200 initially planned were included, explaining why data should be interpreted with caution. In addition, overall survival at 12 months tended to be better using CYC, with an overall survival of $96 \%$ in the CS plus CYC arm compared to $79 \%$ with $C S$ alone $(P=0.08)$, explaining why the interest of CYC remains controversial. Recommendations from the Kidney Disease Improving Global Outcomes (KDIGO) suggest that IgAV-related nephritis in adults should be treated similary as children and should not be used except for CYC in crescentic glomerulonephritis (crescents in $>50 \%$ of the glomeruli) with nephrotic syndrome or rapid degradation of eGFR (28). 
The descriptive analysis of real-life patients may also provide interesting findings on the efficacy of the different therapeutic regimen. In this study, we used several complementary approaches to compare treatment efficacy. First, we did a multivariable analysis taking into account potential confounding factors which was not frequently done in previous studies because of their limited sample size. We also used a propensity score to take into account a potential indication bias as patients treated with CS plus CYC may be more severe at baseline than those treated with CS alone or colchicine (15). We took the propensity score into account in analysis with both adjustment and ponderation by inverse variance. All approaches showed concordant results for the comparison between CS or CS plus CYC versus colchicine. Futhermore, our cohort may have a cohort biased toward more severe disease and the prevalence and course of less serious disease cannot be interpreted to the same extent as more serious disease.

However, this was not the case for the comparison between CS alone and CS plus CYC showing contradictory results according to the statistical methods used. Indeed, multivariable logistic regression model and multivariable propensity score adjusted logistic regression model did not demonstrate any difference between the 2 therapeutic strategies. In contrast, the use of inverse probability weighting on propensity score with or without sensitivity analysis showed that CS plus CYC were more effective than CS alone in achieving a partial of complete response. Propensity score weighting is frequently recommended but could be sensitive to outliers, so no definitive conclusion can be taken for this comparison $(13,14)$. In addition, we cannot exclude bias related to unknown confounders not taken into account in the propensity score. 
These conflicting results reflect that, besides limitations related to the retrospective design and possibly to insufficient power to detect any difference, no firm conclusion can be drawn regarding the comparison between CS alone and CS plus CYC. In addition, the low number of patients receiving colchicine alone or CS plus CYC, as well as the number of non-responder patients, may have limited the power of the study. However, given potential adverse events related to the adjunction of CYC in this condition, CS alone seems appears to be reasonable in first-line in patients with systemic IgAV, except in very severe presentations in which decisions should be made individually.

In conclusion, this series constitutes the largest series reported so far in the literature of adults IgAV. It provides interesting data on clinical and histological presentation and therapeutic efficacy, showing that CS alone appears to be a reasonable first-line therapy in patients with systemic IgAV, while the use of CYC remains controversial. 


\section{References}

1. Jennette JC, Falk RJ, Bacon PA, Basu N, Cid MC, Ferrario F, et al. 2012 revised International Chapel Hill Consensus Conference Nomenclature of Vasculitides. Arthritis Rheum. 2013;65(1):1-11.

2. Gardner-Medwin JM, Dolezalova P, Cummins C, Southwood TR. Incidence of Henoch-Schonlein purpura, Kawasaki disease, and rare vasculitides in children of different ethnic origins. Lancet. 2002;360(9341):1197-202.

3. Yang $\mathrm{YH}$, Hung CF, Hsu CR, Wang LC, Chuang YH, Lin YT, et al. A nationwide survey on epidemiological characteristics of childhood HenochSchonlein purpura in Taiwan. Rheumatology (Oxford). 2005;44(5):618-22.

4. Watts RA, Lane S, Scott DG. What is known about the epidemiology of the vasculitides? Best Pract Res Clin Rheumatol. 2005;19(2):191-207.

5. Gonzalez-Gay MA, Garcia-Porrua C. Systemic vasculitis in adults in northwestern Spain, 1988-1997. Clinical and epidemiologic aspects. Medicine (Baltimore). 1999;78(5):292-308.

6. Pillebout E, Verine J. [Henoch-Schonlein purpura in the adult]. Rev Med Interne. 2014;35(6):372-81.

7. Pillebout E, Thervet E, Hill G, Alberti C, Vanhille P, Nochy D. HenochSchonlein Purpura in adults: outcome and prognostic factors. J Am Soc Nephrol. 2002;13(5):1271-8.

8. Coppo R, Mazzucco G, Cagnoli L, Lupo A, Schena FP. Long-term prognosis of Henoch-Schonlein nephritis in adults and children. Italian Group of Renal Immunopathology Collaborative Study on Henoch-Schonlein purpura. Nephrol Dial Transplant. 1997;12(11):2277-83.

9. Shrestha S, Sumingan N, Tan J, Alhous H, McWilliam L, Ballardie F. Henoch Schonlein purpura with nephritis in adults: adverse prognostic indicators in a UK population. QJM. 2006;99(4):253-65.

10. Garcia-Porrua C, Gonzalez-Louzao C, Llorca J, Gonzalez-Gay MA. Predictive factors for renal sequelae in adults with Henoch-Schonlein purpura. J Rheumatol. 2001;28(5):1019-24.

11. Pillebout E, Alberti C, Guillevin L, Ouslimani A, Thervet E. Addition of cyclophosphamide to steroids provides no benefit compared with steroids alone in treating adult patients with severe Henoch Schonlein Purpura. Kidney Int. 2010;78(5):495-502.

12. Levey AS, Bosch JP, Lewis JB, Greene T, Rogers N, Roth D. A more accurate method to estimate glomerular filtration rate from serum creatinine: a new prediction equation. Modification of Diet in Renal Disease Study Group. Ann Intern Med. 1999;130(6):461-70.

13. Austin PC. An Introduction to Propensity Score Methods for Reducing the Effects of Confounding in Observational Studies. Multivariate Behav Res. 2011;46(3):399-424.

14. Lee BK, Lessier J, Stuart EA. Weight trimming and propensity score weighting. Plos One. 2011;3.

15. Rosenbaum R, Rubin DB. The central role of the propensity score in observational studies for causal effects. Biometrika. 1982;70:41-55.

16. Calvo-Rio V, Loricera J, Mata C, Martin L, Ortiz-Sanjuan F, Alvarez L, et al. Henoch-Schonlein purpura in northern Spain: clinical spectrum of the disease in 417 patients from a single center. Medicine (Baltimore). 2014;93(2):106-13. 
17. Uppal SS, Hussain MA, Al-Raqum HA, Nampoory MR, Al-Saeid K, Al-Assousi $A$, et al. Henoch-Schonlein's purpura in adults versus children/adolescents: $A$ comparative study. Clin Exp Rheumatol. 2006;24(2 Suppl 41):S26-30.

18. Garcia-Porrua C, Calvino MC, Llorca J, Couselo JM, Gonzalez-Gay MA. Henoch-Schonlein purpura in children and adults: clinical differences in a defined population. Semin Arthritis Rheum. 2002;32(3):149-56.

19. Ilan $Y$, Naparstek $Y$. Schonlein-Henoch syndrome in adults and children. Semin Arthritis Rheum. 1991;21(2):103-9.

20. Hung SP, Yang YH, Lin YT, Wang LC, Lee JH, Chiang BL. Clinical manifestations and outcomes of Henoch-Schonlein purpura: comparison between adults and children. Pediatr Neonatol. 2009;50(4):162-8.

21. Audemard-Verger A, Pillebout E, Guillevin L, Thervet E, Terrier B. IgA vasculitis (Henoch-Shonlein purpura) in adults: Diagnostic and therapeutic aspects. Autoimmun Rev. 2015;14(7):579-85.

22. Huber AM, King J, McLaine P, Klassen T, Pothos M. A randomized, placebocontrolled trial of prednisone in early Henoch Schonlein Purpura [ISRCTN85109383]. BMC Med. 2004;2:7.

23. Ronkainen J, Koskimies O, Ala-Houhala M, Antikainen M, Merenmies J, Rajantie J, et al. Early prednisone therapy in Henoch-Schonlein purpura: a randomized, double-blind, placebo-controlled trial. J Pediatr. 2006;149(2):2417.

24. Jauhola O, Ronkainen J, Koskimies O, Ala-Houhala M, Arikoski P, Holtta T, et al. Clinical course of extrarenal symptoms in Henoch-Schonlein purpura: a 6month prospective study. Arch Dis Child. 2010;95(11):871-6.

25. LiuChartapisak W, Opastirakul S, Hodson EM, Willis NS, Craig JC. Interventions for preventing and treating kidney disease in Henoch-Schonlein Purpura (HSP). Cochrane Database Syst Rev. 2009(3):CD005128.

26. Ren $\mathrm{P}$, Han F, Chen L, Xu Y, Wang Y, Chen J. The combination of mycophenolate mofetil with corticosteroids induces remission of HenochSchonlein purpura nephritis. Am J Nephrol. 2012;36(3):271-7.

27. Luqmani RA, Bacon PA, Moots RJ, Janssen BA, Pall A, Emery P, et al. Birmingham Vasculitis Activity Score (BVAS) in systemic necrotizing vasculitis. QJM. 1994;87(11):671-8.

28. Cattran DC, Feehally J, Cook HT, Liu ZH, Fervenza F, Mezzano SA, et al. Kidney disease: Improving global outcomes (KDIGO) glomerulonephritis work group. KDIGO clinical practice guideline for glomerulonephritis. Kidney International Supplements. 2012;2(2):139-274. 


\section{Acknowledgement :}

Corinne Alberti (Paris), Emmanuel Andrès (Strasbourg), Jean-BenoitArlet (Paris), Denis Bagneres (Marseille), Sabine Berthier (Dijon), Benoît Brihaye (St Quentin), Philippe Evon (Bar-le-duc), Sophie Georgin-Lavalle (Paris), Nicolas Girszyn (Rouen), Bruno Gombert (La Rochelle), Maxence Ficheux (Caen), Thierry Lobbedez (Caen), Véronique Le Guern (Paris), Jean Christophe Lega (Lyon), Serge Madaule (Albi), Rosine Mangouka (Chartres), Camille Martinez (Strasbourg), Nadine Meaux-Ruault (Metz), Luc Mouthon (Paris), Laurent Perard (Lyon), Guillaume Queffeulou (Cherbourg), Alexis Regent (Paris), Françoise Sarrot-Reynauld (Grenoble), Laurent Chiche (Marseille), Jérome Février (Caen), Pierre-Yves Hatron (Lille), Eric Hachulla (Lille), Marc Lambert (Lille), Cécile Morice (Caen), Nicolas Bouvier (Caen), Laurence Verneuil (Caen).

\section{Figure legends :}

Figure 1: Efficacy of Corticosteroids or Cyclophosphamide versus Colchicine Figure 2: Efficacy of Corticosteroids plus Cyclophosphamide versus Corticosteroids alone 


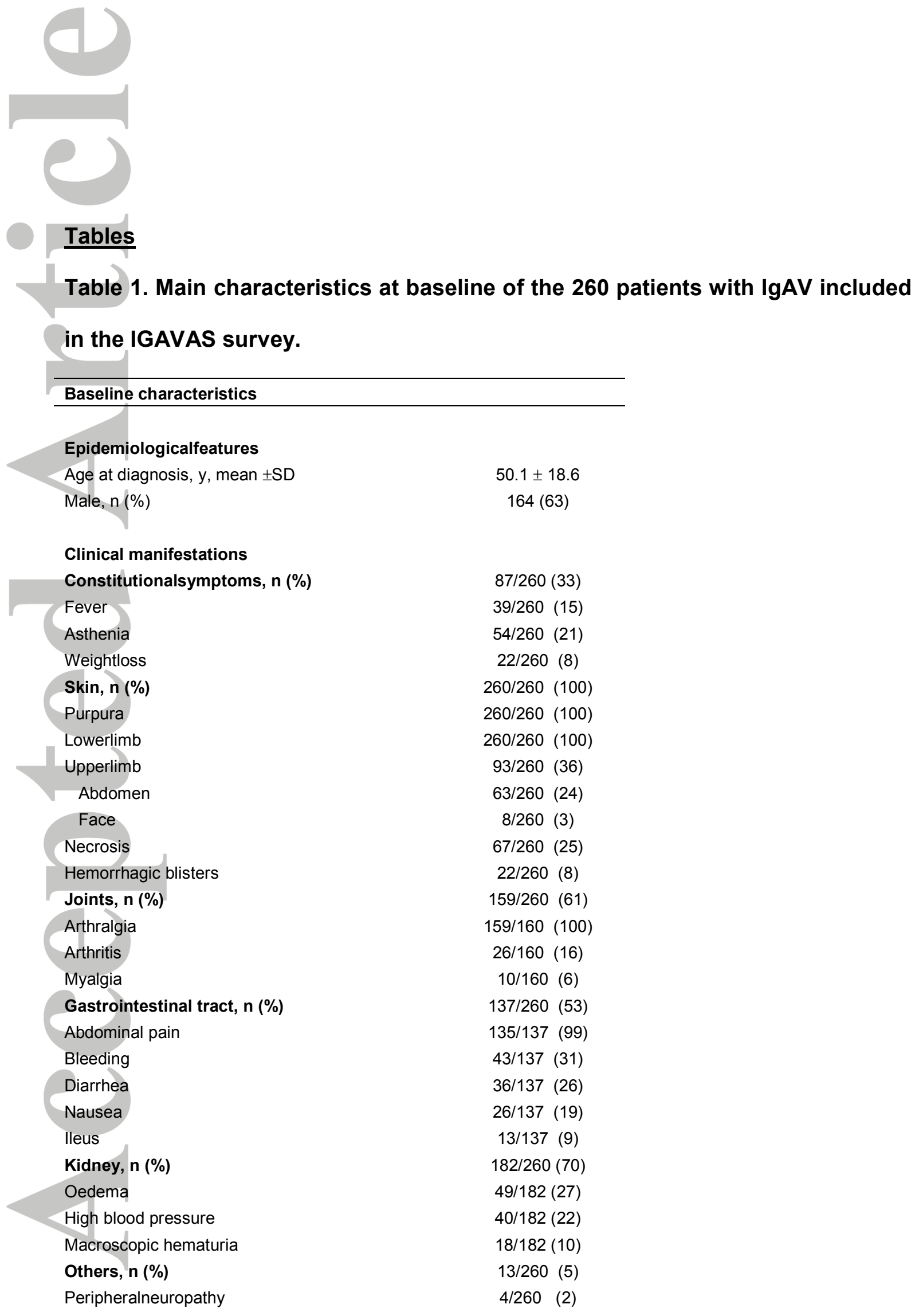




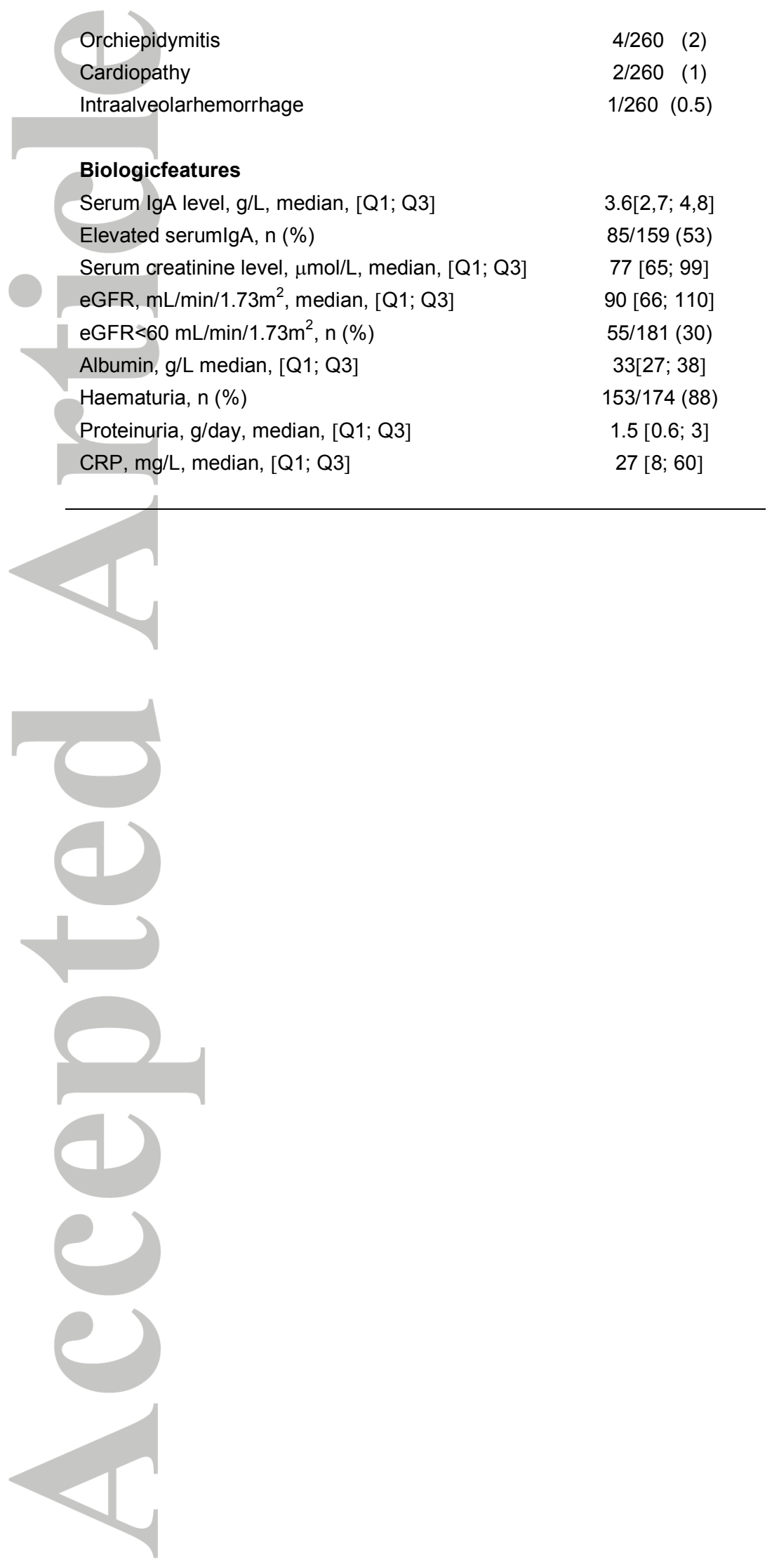

This article is protected by copyright. All rights reserved. 


\section{Table 2. Histological features of the patients with IgAV included in the IGAVAS} survey.

\begin{tabular}{|c|c|}
\hline Histological features & \\
\hline Skin biopsy, n (\%) & $222 / 260(85)$ \\
\hline Leukocytoclastic vasculitis & $205 / 222(92)$ \\
\hline IgAdeposits & $174 / 216(81)$ \\
\hline C3 deposits & $47 / 222(21)$ \\
\hline Fibrinoid necrosis & $59 / 222(27)$ \\
\hline Renalbiopsy & $144 / 182(79)$ \\
\hline IgA mesangial deposits, $\mathrm{n}(\%)$ & $142 / 144(99)$ \\
\hline Extracapillaryproliferation, n (\%) & $59 / 144(41)$ \\
\hline Fibrinoid necrosis, n (\%) & $46 / 144(32)$ \\
\hline Glomerularsclerosis, n (\%) & $47 / 144(33)$ \\
\hline$\%$ of glomerular sclerosis, median [Q1; Q3] & $11[7 ; 20]$ \\
\hline$\%$ of interstitial fibrosis, median [Q1; Q3] & $15[10 ; 21]$ \\
\hline Tubulointerstitial nephritis, n (\%) & $44 / 144(31)$ \\
\hline Classification, n (\%) & \\
\hline Class 1 & $2 / 67(3)$ \\
\hline Class 2 & $33 / 67(49)$ \\
\hline Class $3 a$ & $18 / 67(27)$ \\
\hline Class $3 \mathrm{~b}$ & 9/67 (13) \\
\hline Class 4 & $4 / 67(6)$ \\
\hline Class 5 & $1 / 67(2)$ \\
\hline
\end{tabular}




\section{Table 3. Characteristics of the patients according to treatment received}

\begin{tabular}{|c|c|c|c|c|c|}
\hline Characteristics & $\begin{array}{c}C S+C Y C \\
n=35\end{array}$ & $\begin{array}{c}\text { CS } \\
n=122\end{array}$ & $\begin{array}{c}\text { Colchicine } \\
\text { only } \\
n=27\end{array}$ & $\begin{array}{c}\text { No therapy } \\
n=66\end{array}$ & $\mathbf{P}$ \\
\hline $\begin{array}{l}\text { Age, mean (SD) } \\
\text { Gender, n (\%) }\end{array}$ & $47(18)$ & $51(20)$ & $45(16)$ & $51(18)$ & $\begin{array}{l}0.36 \\
\mathbf{0 . 0 0 4}\end{array}$ \\
\hline Men & $31(89)$ & $76(62)$ & $15(56)$ & $35(53)$ & \\
\hline Women & $4(11)$ & $45(38)$ & $12(44)$ & $31(47)$ & \\
\hline Skin involvement, n (\%) & $35(100)$ & $122(100)$ & 27 (100) & 66 (100) & - \\
\hline Necrotic purpura & $17(49)$ & $30(25)$ & $5(19)$ & $12(18)$ & 0.006 \\
\hline Fibrinoid necrosis at biopsy & $9(26)$ & $33(27)$ & $4(15)$ & $11(17)$ & 0.28 \\
\hline Joint involvement, $\mathbf{n}(\%)$ & $23(66)$ & $79(65)$ & $16(59)$ & $32(48)$ & 0.15 \\
\hline Renal involvement, n (\%) & $30(86)$ & $93(76)$ & $11(41)$ & $39(59)$ & 0.0001 \\
\hline Proteinuria $>1 \mathrm{~g} / \mathrm{d}, \mathrm{n}(\%)$ & $24(69)$ & $53(43)$ & $4(15)$ & $17(26)$ & $<0.0001$ \\
\hline Proteinuria $>3 \mathrm{~g} / \mathrm{d}, \mathrm{n}(\%)$ & $13(37)$ & $24(20)$ & $1(4)$ & $5(7)$ & 0.0004 \\
\hline Hematuria, n (\%) & $27(77)$ & $79(65)$ & $9(33)$ & $31(47)$ & 0.0005 \\
\hline Creatinine, median [Q1; Q3] & $80(70-117)$ & $80(66-111)$ & $75(66-85)$ & $71(62-86)$ & 0.02 \\
\hline eGFR, median [Q1; Q3] & $90(50-112)$ & $90(61-108)$ & $96(87-105)$ & $98(80-111)$ & 0.23 \\
\hline Biopsy performed, n (\%) & $29(83)$ & $69(57)$ & $8(30)$ & $29(44)$ & $<0.0001$ \\
\hline Endocapillary GN, n (\%) & $18(62)$ & $33(48)$ & $3(37)$ & $9(31)$ & \\
\hline Extracapillary GN, n (\%) & $14(48)$ & $35(51)$ & $0(0)$ & $5(17)$ & \\
\hline GI involvement, $\mathrm{n}(\%)$ & $26(74)$ & $75(61)$ & $7(26)$ & $21(32)$ & $<0.0001$ \\
\hline lleus & $3(9)$ & $8(7)$ & $0(0)$ & $2(3)$ & $0.38^{*}$ \\
\hline Bleeding & $14(40)$ & 23 (19) & $1(4)$ & $2(3)$ & $<0.0001$ \\
\hline Surgical abdomen & $3(9)$ & $2(2)$ & $0(0)$ & $0(0)$ & $0.054^{*}$ \\
\hline
\end{tabular}

CS : corticosteroids ; CYC :cyclophosphamide ; GN :glomerulonephritis, GI :gastrointestinal *Fisher exact test

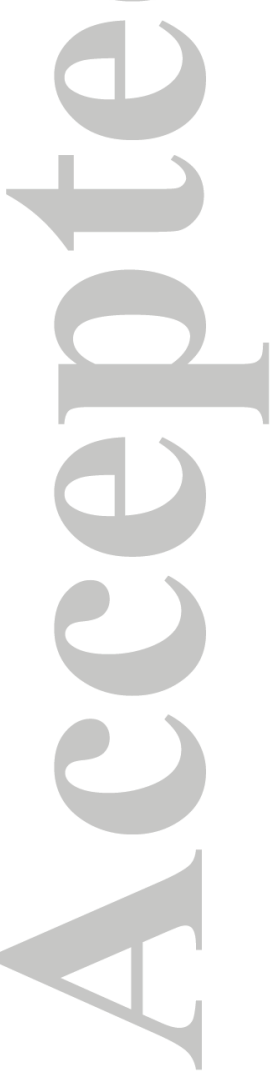


Table 4. Characteristics of patients according to the achievement of partial or complete response in comparison with those without any response.

\begin{tabular}{|c|c|c|c|}
\hline Characteristics & $\begin{array}{c}\begin{array}{c}\text { Response } \\
\mathrm{n}=97\end{array} \\
\end{array}$ & $\begin{array}{c}\text { No response } \\
n=30\end{array}$ & $\mathbf{p}$ \\
\hline Age, mean (SD) & $49(19)$ & $48(17)$ & 0.72 \\
\hline Gender, n (\%) & & & 0.16 \\
\hline Men & $61(63)$ & $23(77)$ & \\
\hline Women & $36(37)$ & $7(23)$ & \\
\hline Skin involvement, n (\%) & 97 (100) & $30(100)$ & NA \\
\hline Necrotic purpura & $30(31)$ & $9(30)$ & 0.92 \\
\hline Fibrinoid necrosis at biopsy & $25(26)$ & $8(27)$ & 0.92 \\
\hline Joint involvement, $n(\%)$ & $65(67)$ & $16(53)$ & 0.17 \\
\hline Renal involvement, n (\%) & $69(71)$ & $21(70)$ & 0.90 \\
\hline Proteinuria $>1$ g/d, n (\%) & $46(47)$ & $16(53)$ & 0.57 \\
\hline Proteinuria $>3 \mathrm{~g} / \mathrm{d}, \mathrm{n}(\%)$ & $22(23)$ & $9(30)$ & 0.41 \\
\hline Hematuria, $\mathrm{n}(\%)$ & $58(60)$ & $17(57)$ & 0.76 \\
\hline Creatinin, median [Q1; Q3] & $76(67-104)$ & $88(78-110)$ & 0.31 \\
\hline eGFR, median [Q1; Q3] & $95(65-111)$ & $86(57-96)$ & 0.14 \\
\hline Biopsy performed, n (\%) & $59(61)$ & $19(63)$ & 0.80 \\
\hline Endocapillary GN, n (\%) & $31(53)$ & $11(58)$ & \\
\hline Extracapillary GN, n (\%) & $30(51)$ & $8(42)$ & \\
\hline GI involvement, $n(\%)$ & $55(57)$ & $15(50)$ & 0.52 \\
\hline lleus & $4(4)$ & $1(3)$ & $1^{*}$ \\
\hline Bleeding & $28(29)$ & $4(13)$ & 0.09 \\
\hline Surgical abdomen & $2(2)$ & $1(3)$ & $0.56^{*}$ \\
\hline First line treatment, $\mathrm{n}(\%)$ & & & 0.17 \\
\hline $\operatorname{CS}(n=80)$ & $64(66)$ & $16(53)$ & \\
\hline$C S+\operatorname{CYC}(n=30)$ & $23(24)$ & $7(23)^{\prime}$ & \\
\hline Colchicine $(n=17)$ & $10(10)$ & $7(23)$ & \\
\hline
\end{tabular}

CS : corticosteroids ; CYC :cyclophosphamide ; GN :glomerulonephritis, GI :gastrointestinal * Fisher exact test.

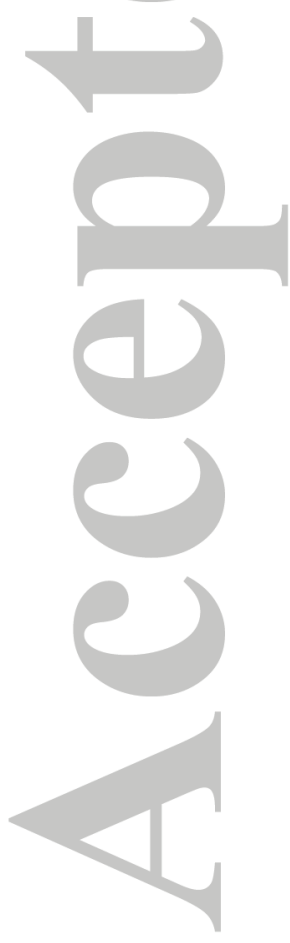




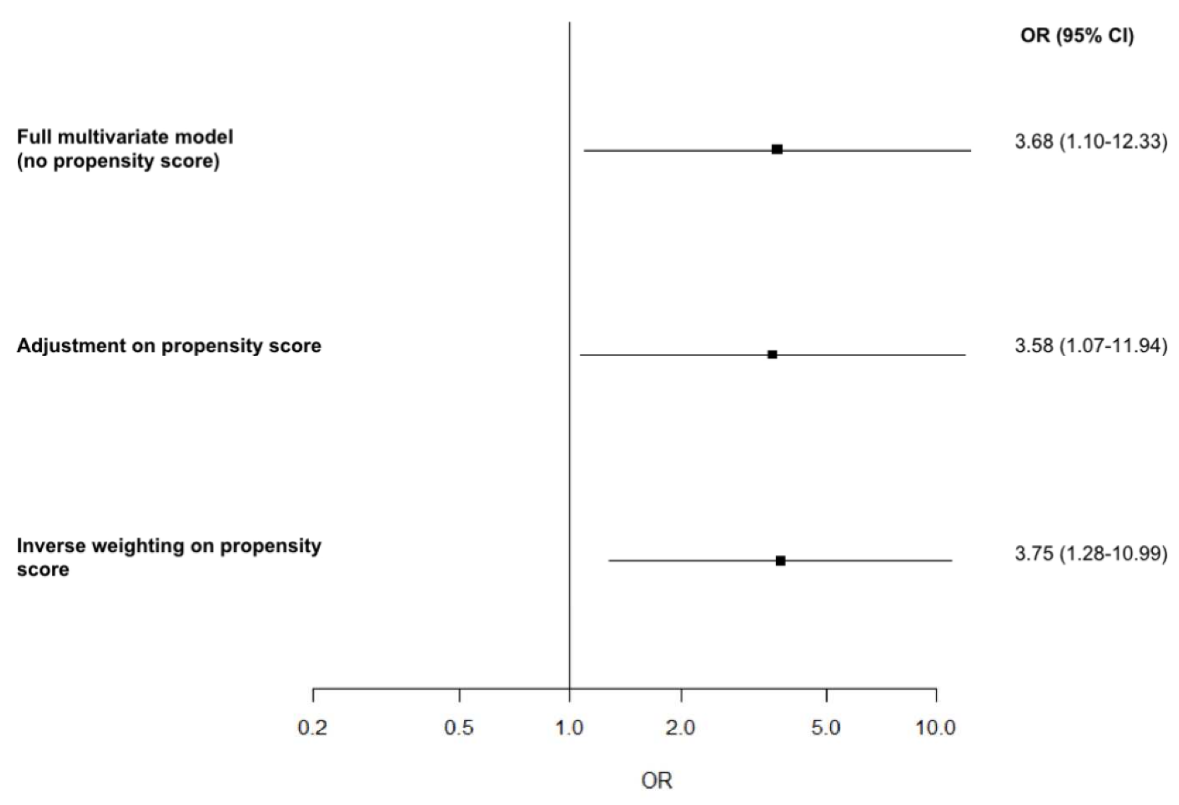

Efficacy of Corticosteroids or Cyclophosphamide versus Colchicine 


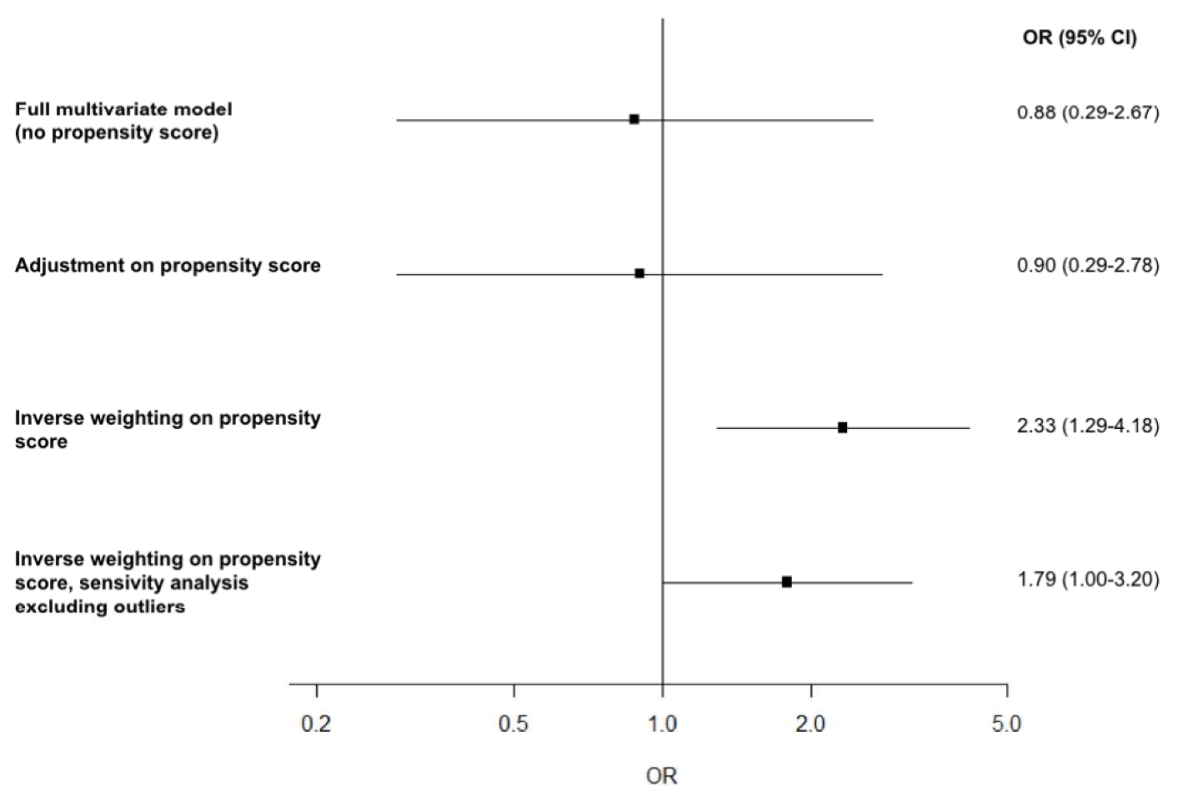

Efficacy of Corticosteroids plus Cyclophosphamide versus Corticosteroids alone

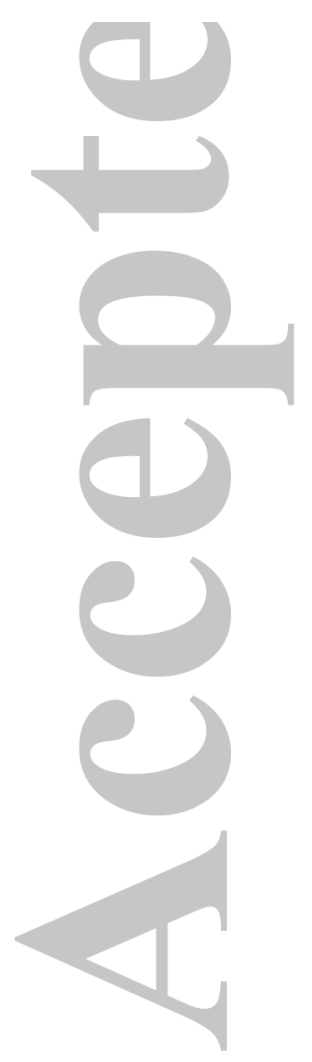

John Wiley \& Sons

This article is protected by copyright. All rights reserved. 